\title{
Wind Farm to Weak-Grid Connection using UPQC Custom Power Device
}

\author{
M.F. Farias \\ Facultad de Ingeniería \\ Universidad Nacional de La Plata \\ CC91, La Plata, Argentina \\ Fundacion YPF \\ Email: marcelo.farias@ing.unlp.edu.ar
}

\author{
P.E. Battaiotto \\ Facultad de Ingeniería \\ Universidad Nacional de La Plata \\ CC91, La Plata, Argentina \\ Email: pedro@ing.unlp.edu.ar
}

\author{
M.G. Cendoya \\ Facultad de Ingeniería \\ Universidad Nacional de La Plata \\ CC91, La Plata, Argentina \\ Consejo Nacional de Investigaciones \\ Científicas y Tecnológicas (CONICET) \\ Email: cendoya@ing.unlp.edu.ar
}

\begin{abstract}
Wind Farms (WF) employing squirrel cage induction generator (SCIG) directly connected to the grid, represent a large percentage of the wind energy conversion systems around the world. In facilities with moderated power generation, the WF are connected through medium voltage (MV) distribution headlines. A situation commonly found in such scheme is that the power generated is comparable to the transport capacity of the grid. This case is known as Wind Farm to Weak Grid Connection, and its main problem is the poor voltage regulation at the point of common coupling (PCC). Thus, the combination of weak grids, wind power fluctuation and system load changes produce disturbances in the PCC voltage, worsening the Power Quality and WF stability. This situation can be improved using control methods at generator level, or compensation techniques at PCC. In case of wind farms based on SCIG directly connected to the grid, is necessary to employ the last alternative. Custom power devices technology (CUPS) result very usefull for this kind of application. In this paper is proposed a compensation strategy based on a particular CUPS device, the Unified Power Quality Compensator (UPQC). A customized internal control scheme of the UPQC device was developed to regulate the voltage in the WF terminals, and to mitigate voltage fluctuations at grid side. The internal control strategy is based on the management of active and reactive power in the series and shunt converters of the UPQC, and the exchange of power between converters through UPQC DC-Link. This approach increase the compensation capability of the UPQC with respect to other custom strategies that use reactive power only.Simulations results show the effectiveness of the proposed compensation strategy for the enhancement of Power Quality and Wind Farm stability.
\end{abstract}

Index Terms-Wind Energy, UPQC, voltage fluctuation, weak grid

\section{INTRODUCTION}

The location of generation facilities for wind energy is determined by wind energy resource availability, often far from high voltage (HV) power transmission grids and major consumption centers [1].

In case of facilities with medium power ratings, the WF is connected through medium voltage (MV) distribution headlines. A situation commonly found in such scheme is that the power generated is comparable to the transport power capacity of the power grid to which the WF is connected, also known as weak grid connection. The main feature of this type of connections, is the increased voltage regulation sensitivity to changes in load [2]. So, the system's ability to regulate voltage at the point of common coupling (PCC) to the electrical system is a key factor for the successful operation of the WF.

Also, is well known that given the random nature of wind resources, the WF generates fluctuating electric power.These fluctuations have a negative impact on stability and power quality in electric power systems. [3]

Moreover, in exploitation of wind resources, turbines employing squirrel cage induction generators (SCIG) have been used since the beginnings. The operation of SCIG demands reactive power, usually provided from the mains and/or by local generation in capacitor banks [4], [5]. In the event that changes occur in its mechanical speed, ie due to wind disturbances, so will the WF active(reactive) power injected(demanded) into the power grid, leading to variations of WF terminal voltage because of system impedance. This power disturbances propagate into the power system, and can produce a phenomenon known as "flicker", which consists of fluctuations in the illumination level caused by voltage variations. Also, the normal operation of WF is impaired due to such disturbances. In particular for the case of "weak grids", the impact is even greater.

In order to reduce the voltage fluctuations that may cause "flicker", and improve WF terminal voltage regulation, several solutions have been posed. The most common one is to upgrade the power grid, increasing the short circuit power level at the point of common coupling PCC, thus reducing the impact of power fluctuations and voltage regulation problems [5].

In recent years, the technological development of high power electronics devices has led to implementation of electronic equipment suited for electric power systems, with fast response compared to the line frequency. These active compensators allow great flexibility in: a) controlling the power flow in transmission systems using Flexible AC Transmission System (FACTS) devices, and b) enhancing the power quality in distribution systems employing Custom Power System (CUPS) devices [6] [9]. The use of these active compensators to improve integration of wind energy in weak grids is the approach adopted in this work.

In this paper we propose and analyze a compensation strategy using an UPQC, for the case of SCIG-based WF, 


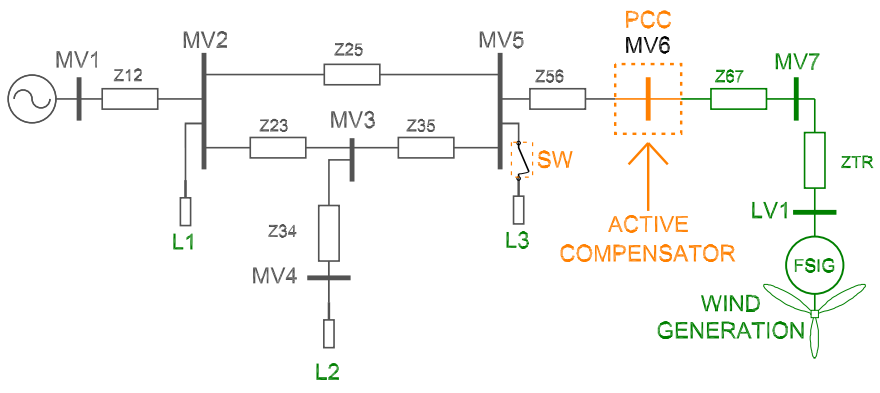

Fig. 1. Study case power system

connected to a weak distribution power grid. This system is taken from a real case [7].

The UPQC is controlled to regulate the WF terminal voltage, and to mitigate voltage fluctuations at the point of common coupling (PCC), caused by system load changes and pulsating WF generated power, respectively. The voltage regulation at WF terminal is conducted using the UPQC series converter, by voltage injection "in phase" with PCC voltage. On the other hand, the shunt converter is used to filter the WF generated power to prevent voltage fluctuations, requiring active and reactive power handling capability. The sharing of active power between converters, is managed through the common DC link.

Simulations were carried out to demonstrate the effectiveness of the proposed compensation approach.

\section{SYSTEM DESCRIPTION AND MODELLING}

\section{A. System description}

Fig. 1 depicts the power system under consideration in this study.

The WF is composed by 36 wind turbines using squirrel cage induction generators, adding up to $21.6 \mathrm{MW}$ electric power. Each turbine has attached fixed reactive compensation capacitor banks (175kVAr), and is connected to the power grid via $630 \mathrm{KVA} 0.69 / 33 \mathrm{kV}$ transformer. This system is taken from [7], and represents a real case.

The ratio between short circuit power and rated WF power, give us an idea of the "connection weakness". Thus considering that the value of short circuit power in MV6 is $S_{S C} \simeq 120 M V A$ this ratio can be calculated:

$$
r=\frac{S_{S C}}{P_{W F}} \simeq 5.5
$$

Values of $r<20$ are considered as a "weak grid" connection [2].

\section{B. Turbine rotor and associated disturbances model}

The power that can be extracted from a wind turbine, is determined by the following expression:

$$
P=\frac{1}{2} \cdot \rho \cdot \pi \cdot R^{2} \cdot v^{3} \cdot C_{P}
$$

Where $\rho$ is air density, $R$ the radius of the swept area, $v$ the wind speed, and $C_{P}$ the power coefficient. For the considered turbines $(600 \mathrm{~kW})$ the values are $R=31.2 \mathrm{~m}$, $\rho=1.225 \mathrm{~kg} / \mathrm{m}^{3}$ and $C_{P}$ calculation is taken from [8].

Then, a complete model of the WF is obtained by turbine aggregation; this implies that the whole WF can be modeled by only one equivalent wind turbine, whose power is the arithmetic sum of the power generated by each turbine according to the following equation:

$$
P_{T}=\sum_{i=1 \cdots 36} P_{i}
$$

Moreover, wind speed $v$ in (1) can vary around its average value due to disturbances in the wind flow. Such disturbances can be classified as deterministic and random. The firsts are caused by the asymmetry in the wind flow "seen" by the turbine blades due to "tower shadow" and/or due to the atmospheric boundary layer, while the latter are random changes known as "turbulence". For our analysis, wind flow disturbance due to support structure (tower) is considered, and modeled by a sinusoidal modulation superimposed to the mean value of $v$. The frequency for this modulation is $3 \cdot N_{\text {rotor }}$ for the three-bladed wind turbine, while its amplitude depends on the geometry of the tower. In our case we have considered a mean wind speed of $12 \mathrm{~m} / \mathrm{s}$ and the amplitude modulation of $15 \%$.

The effect of the boundary layer can be neglected compared to those produced by the shadow effect of the tower in most cases [3]. It should be noted that while the arithmetic sum of perturbations occurs only when all turbines operate synchonously and in phase, this is the case that has the greatest impact on the power grid (worst case), since the power pulsation has maximum amplitude. So, turbine aggregation method is valid.

\section{Model of induction generator}

For the squirrel cage induction generator the model available in Matlab/Simulink SimPowerSystems(C) libraries is used. It consists of a fourth-order state-space electrical model and a second-order mechanical model [5].

\section{Dynamic compensator model}

The dynamic compensation of voltage variations is performed by injecting voltage in series and active-reactive power in the MV6 (PCC) busbar; this is accomplished by using an unified type compensator UPQC [9]. In Fig.2 we see the basic outline of this compensator; the busbars and impedances numbering is referred to Fig.1.

The operation is based on the generation of three phase voltages, using electronic converters either voltage source type (VSI-Voltage Source Inverter) or current source type (CSICurrent Source Inverter). VSI converter are preferred because of lower DC link losses and faster response in the system than CSI [9]. The shunt converter of UPQC is responsible for injecting current at PCC, while the series converter generates voltages between PCC and U1, as illustrated in the phasor diagram of Fig.3. An important feature of this compensator is the operation of both VSI converters (series and shunt) sharing 


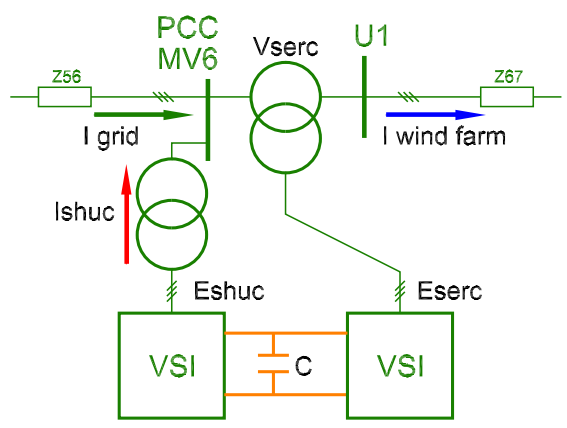

Fig. 2. Block diagram of UPQC

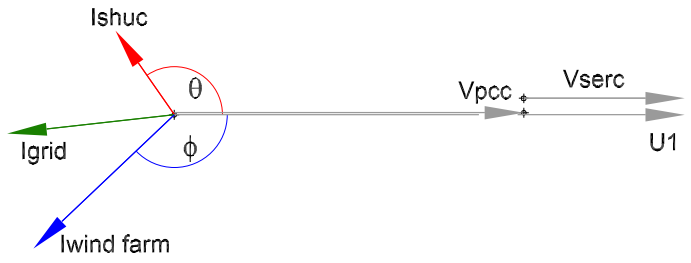

Fig. 3. Phasor diagram of UPQC

the same DC-bus, which enables the active power exchange between them.

We have developed a simulation model for the UPQC based on the ideas taken from [10]. Since switching control of converters is out of the scope of this work, and considering that higher order harmonics generated by VSI converters are outside the bandwidth of significance in the simulation study, the converters are modelled using ideal controlled voltage sources. Fig.4 shows the adopted model of power side of UPQC.

The control of the UPQC, will be implemented in a rotating frame $d q 0$ using Park's transformation (eq.3-4)

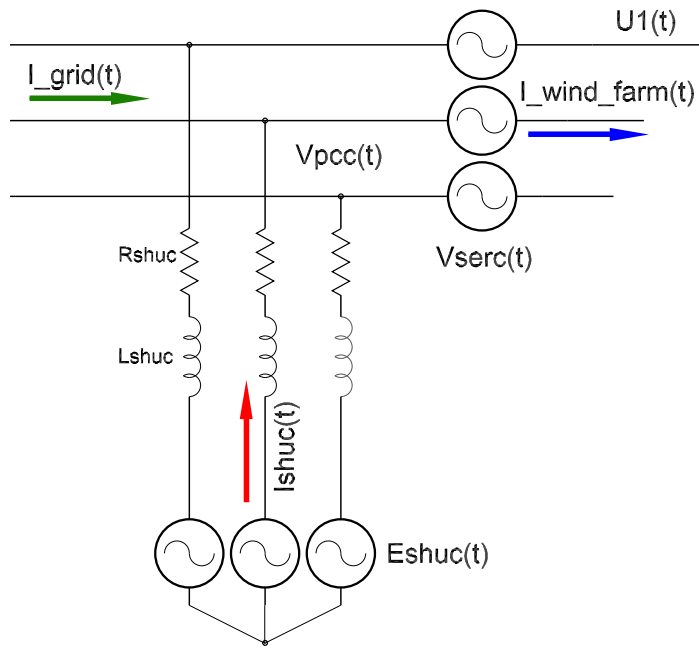

Fig. 4. Power stage compensator model. AC Side

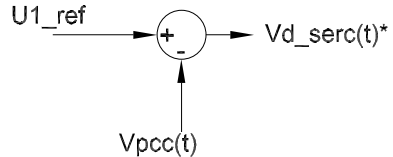

Fig. 5. Series compensator controller

$$
\begin{gathered}
T=\frac{2}{3} \cdot\left[\begin{array}{ccc}
\sin (\theta) & \sin \left(\theta-\frac{2 \pi}{3}\right) & \sin \left(\theta+\frac{2 \pi}{3}\right) \\
\cos (\theta) & \cos \left(\theta-\frac{2 \pi}{3}\right) & \cos \left(\theta+\frac{2 \pi}{3}\right) \\
\frac{1}{2} & \frac{1}{2} & \frac{1}{2}
\end{array}\right] \\
{\left[\begin{array}{c}
f_{d} \\
f_{q} \\
f_{0}
\end{array}\right]=T \cdot\left[\begin{array}{c}
f_{a} \\
f_{b} \\
f_{c}
\end{array}\right]}
\end{gathered}
$$

Where $f_{i=a, b, c}$ represents either phase voltage or currents, and $f_{i=d, q, 0}$ represents that magnitudes transformed to the $d q o$ space.

This transformation allows the alignment of a rotating reference frame with the positive sequence of the PCC voltages space vector. To accomplish this, a reference angle $\theta$ synchronized with the PCC positive sequence fundamental voltage space vector is calculated using a Phase Locked Loop (PLL) system. In this work, an "instantaneous power theory" based PLL has been implemented [11].

Under balance steady-state conditions, voltage and currents vectors in this synchronous reference frame are constant quantities. This feature is useful for analysis and decoupled control.

\section{UPQC CONTROL STRATEGY}

The UPQC serial converter is controlled to maintain the WF terminal voltage at nominal value (see U1 bus-bar in Fig.4), thus compensating the PCC voltage variations. In this way, the voltage disturbances coming from the grid cannot spread to the WF facilities. As a side effect, this control action may increase the low voltage ride-through (LVRT) capability in the occurrence of voltage sags in the WF terminals [4], [9].

Fig. 5 shows a block diagram of the series converter controller. The injected voltage is obtained substracting the PCC voltage from the reference voltage, and is phase-aligned with the PCC voltage (see Fig.3).

On the other hand, the shunt converter of UPQC is used to filter the active and reactive power pulsations generated by the WF. Thus, the power injected into the grid from the WF compensator set will be free from pulsations, which are the origin of voltage fluctuation that can propagate into the system. This task is achieved by appropiate electrical currents injection in PCC. Also, the regulation of the DC bus voltage has been assigned to this converter.

Fig.6 shows a block diagram of the shunt converter controller. This controller generates both voltages commands 

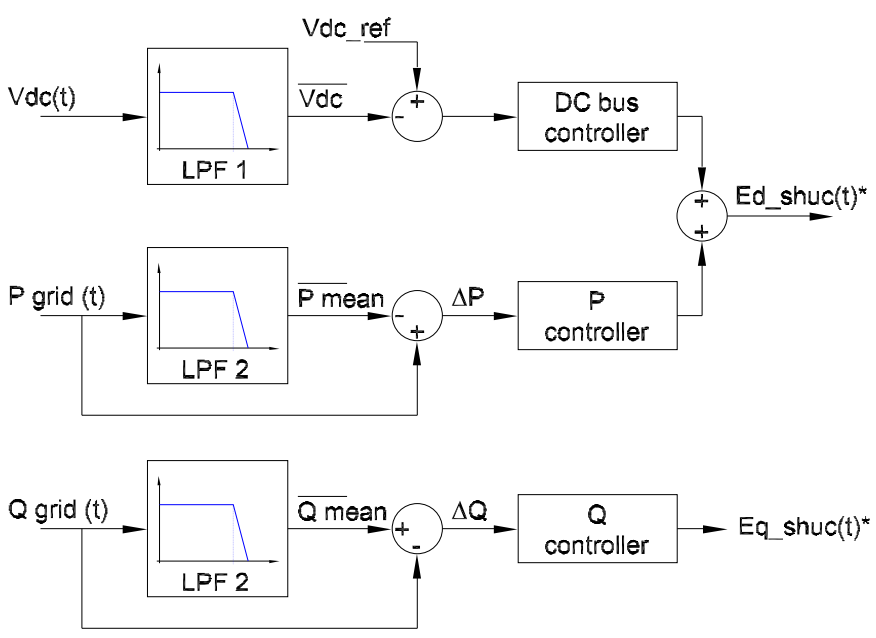

Fig. 6. Shunt compensator controller

$E_{d \_s h u C}{ }^{*}$ and $E_{q \_s h u C}{ }^{*}$ based on power fluctuations $\Delta P$ and $\Delta \bar{Q}$, respectively. Such deviations are calculated substracting the mean power from the instantaneus power measured in PCC.

The mean values of active and reactive power are obtained by low-pass filtering, and the bandwidth of such filters are chosen so that the power fluctuation components selected for compensation, fall into the flicker band as stated in IEC610004-15 standard.

In turn, $E_{d \_s h u C}{ }^{*}$ also contains the control action for the DC-bus voltage loop. This control loop will not interact with the fluctuating power compensation, because its components are lower in frequency than the flicker-band.

The powers $P_{\text {shuC }}$ and $Q_{\text {shuC }}$ are calculated in the rotating reference frame, as follows:

$$
\begin{aligned}
& P_{\text {shuC }}(t)=\frac{3}{2} \cdot V_{d}^{P C C}(t) \cdot I_{d}^{\text {shuC }}(t) \\
& Q_{\text {shuC }}(t)=-\frac{3}{2} \cdot V_{d}^{P C C}(t) \cdot I_{q}^{\text {shuC }}(t)
\end{aligned}
$$

Ignoring PCC voltage variation, these equations can be written as follows.

$$
\begin{aligned}
P_{\text {shuC }}(t) & =k_{p}^{\prime} \cdot I_{d \_s h u C}(t) \\
Q_{\text {shuC }}(t) & =k_{q}^{\prime} \cdot I_{q \_s h u C}(t)
\end{aligned}
$$

Taking in consideration that the shunt converter is based on a VSI, we need to generate adecuate voltages to obtain the currents in (6). This is achieved using the VSI model proposed in [10], leading to a linear relationship between the generated power and the controller voltages. The resultant equations are:

$$
\begin{aligned}
P_{\text {shuC }}(t) & =k_{p}^{\prime \prime} \cdot E_{d \_s h u C}{ }^{*}(t) \\
Q_{\text {shuC }}(t) & =k_{q}^{\prime \prime} \cdot E_{q \_s h u C}{ }^{*}(t)
\end{aligned}
$$

$\mathrm{P}$ and $\mathrm{Q}$ control loops comprise proportional controllers, while DC-bus loop, a PI controller.

In summary, in the proposed strategy the UPQC can be seen as a "power buffer", leveling the power injected into the power

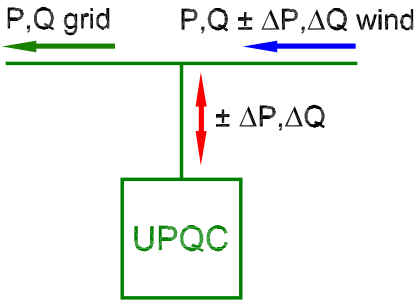

Fig. 7. Power buffer concept

system grid. The Fig.7 illustrates a conceptual diagram of this mode of operation.

It must be remarked that the absence of an external DC source in the UPQC bus, forces to maintain zero-average power in the storage element installed in that bus. This is accomplished by a proper design of DC voltage controller.

Also, it is necessary to note that the proposed strategy cannot be implemented using other CUPS devices like D-Statcom or DVR. The power buffer concept may be implemented using a DStatcom, but not using a DVR. On the other hand, voltage regulacion during relatively large disturbances, cannot be easily coped using reactive power only from DStatcom; in this case, a DVR device is more suitable.

\section{SimUlation RESULTS AND DISCUSSION}

The model of the power system scheme illustrated in Fig.1, including the controllers with the control strategy detailed in section III, was implemented using Matlab/Simulink $\mathbb{R}$ software. Numerical simulations were performed to determine and then compensate voltage fluctuation due to wind power variation, and voltage regulation problems due to a sudden load connection. The simulation was conducted with the following chronology:

- at $t=0.0^{\prime \prime}$ the simulation starts with the series converter and the DC-bus voltage controllers in operation.

- at $t=0.5^{\prime \prime}$ the tower shadow effect starts;

- at $t=3.0^{\prime \prime} \mathrm{Q}$ and $\mathrm{P}$ control loops(see Fig.6) are enabled;

- at $t=6.0^{\prime \prime} \mathrm{L} 3$ load is connected.

- at $t=6.0^{\prime \prime}$ L3 load is disconnected.

\section{A. Compensation of voltage fluctuation}

Simulation results for $0<t<6$ are shown in Fig.8.

At $t=0.5^{\prime \prime}$ begins the cyclical power pulsation produced by the tower shadow effect. As was mentioned, the tower shadow produces variation in torque, and hence in the active and reactive WF generated power. For nominal wind speed condition, the power fluctuation frequency is $\mathrm{f}=3.4 \mathrm{~Hz}$, and the amplitude of the resulting voltage variation at PCC, expressed as a percentage is:

$$
\frac{\Delta U}{U_{\text {rated }}}=1.50 \%
$$

This voltage fluctuation is seen in middle curve of Fig.8 for $0.5<t<3$.

The fluctuation value is higher than the maximum allowed by the IEC61000-4-15 standard [12]. This means that even in 

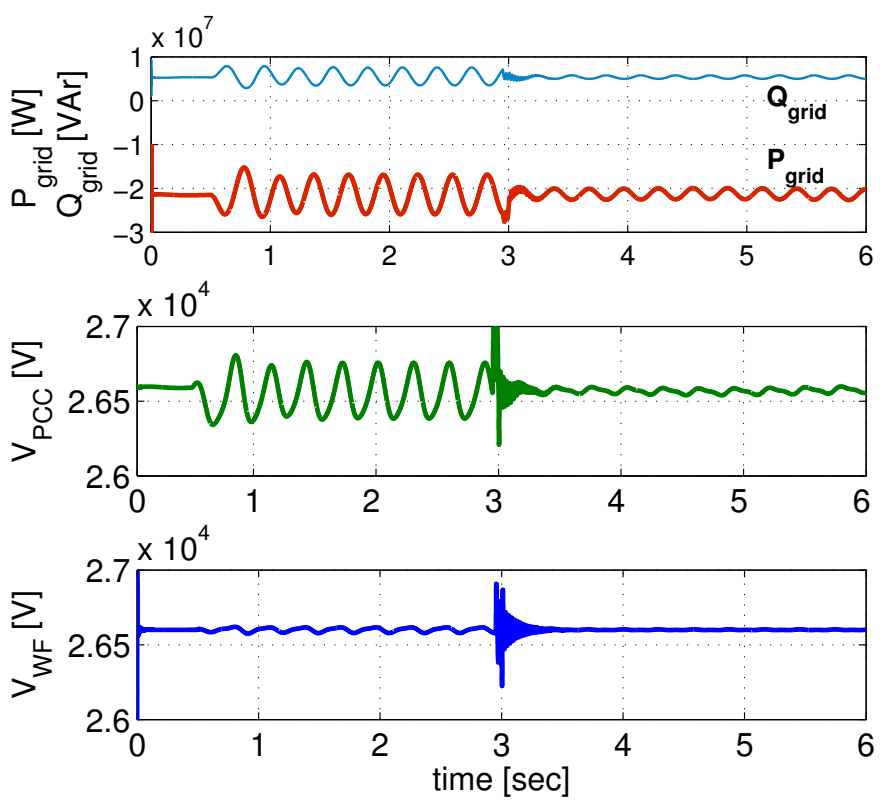

Fig. 8. Upper curve: active and reactive power demand at power grid side. Middle curve: PCC voltage. Lower curve: WF terminal voltages

normal operation, the WF impacts negatively on the System Power Quality.

At $t=3.0^{\prime \prime}$ the active and reactive power pulsations are attenuated because the $\mathrm{P}$ and $\mathrm{Q}$ controllers come into action.

The amplitud of the PCC voltage fluctuation is reduced from its original value of $1.6 \%$ (without compensation) to this new value:

$$
\frac{\Delta U}{U_{\text {rated }}}=0.18 \%
$$

This value agrees with IEC standard [12], since is lower than the specified permisible maximum limit, $0.5 \%$ at $3.4 \mathrm{~Hz}$.

In the lower curve of Fig.8, WF terminal voltage behaviour is shown; the series converter action maintains WF terminal voltage constant, regardless of the PCC voltage behavior.

The pulsation of active power and voltage at the UPQC DC-side, are shown in Fig.9.

As can be observed in the upper curve, the series converter requires negligible power to operate, while the shunt converter demands a high instantaneus power level from the capacitor when compensating active power fluctuation. Compensation of reactive powers has no influence on the DC side power [13].

The DC-bus has voltage level limitations in accordance with the VSI's operational characteristics. As the fluctuating active power is handled by the capacitor, its value needs to be selected so that the "ripple" in the DC voltage is kept within a narrow range.

In our case, we have considered a capacitor size $C=0.42 \mathrm{~F}$.

This high value can be easily obtained by using emerging technologies based capacitors, such as double-layer capacitors, also known as ultracapacitors.

The compensation action can also be seen by observing the trajectory of the power grid current space vector in the dq
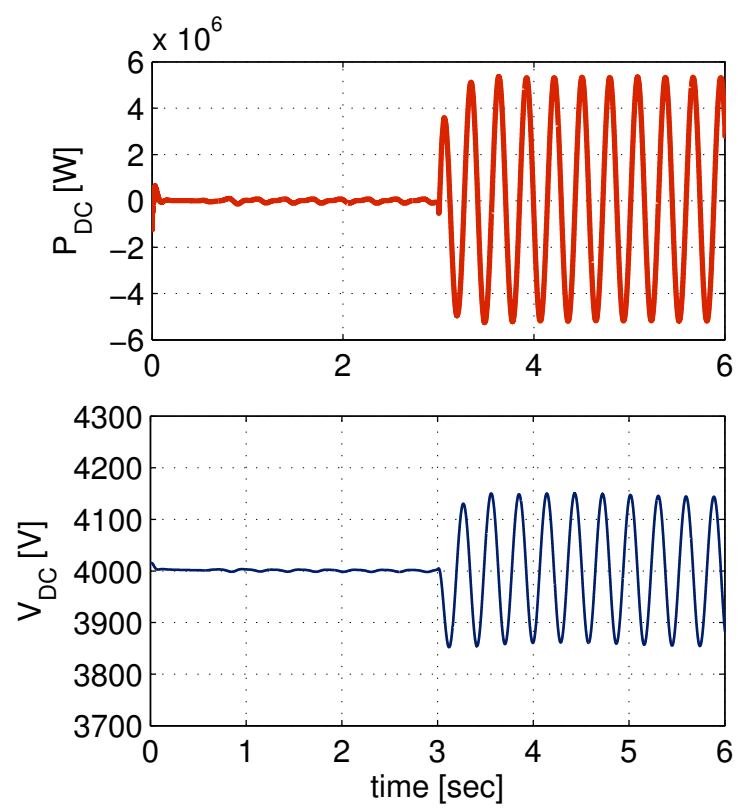

Fig. 9. Power and voltage of the capacitor in the DC-Bus.

plane. The Fig.10 shows this trajectory with and without compensation. The horizontal axis represents the $I_{\text {grid }}$ component in phase with PCC voltage (also called "active component"); and the vertical one, the quadrature component (or "reactive component"). In that figure is observed the reduction in $\Delta I_{d}$ and $\Delta I_{q}$.

It is neccesary to note that the sign of the measured grid current is considered positive when it flows towards the park.

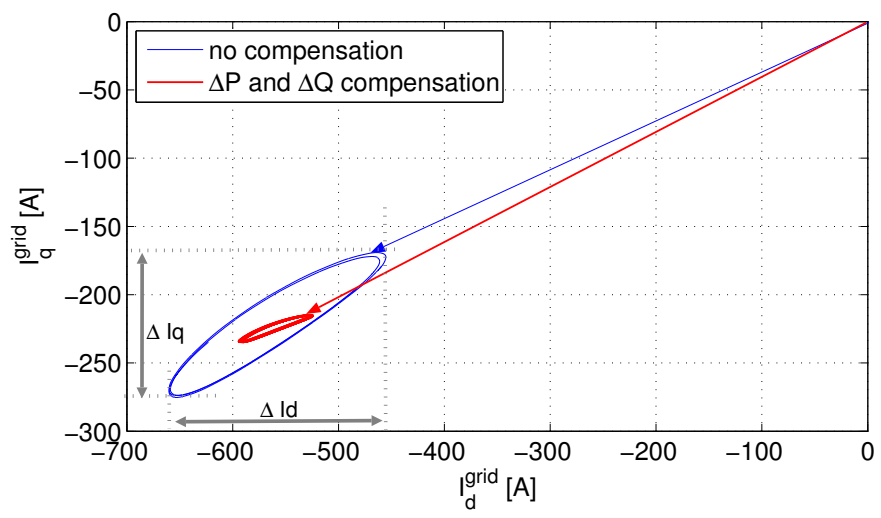

Fig. 10. Behavior of the power grid current vector within dq0 reference frame

\section{B. Voltage regulation}

As been stated in Secc.III, the UPQC is also operated to maintain the WF terminal voltage constant, rejecting PCC voltage variations, due to events like sudden connection/disconnection of loads, power system faults, etc. A sudden connection of load is performed at $t=6^{\prime \prime}$, by closing L3 switch (SW) in Fig.1. This load is rated at $P_{L 3}=9.2 M W$ and $Q_{L 3}=9.25 M W$. Such load is then disconnected at $t=10^{\prime \prime}$. 

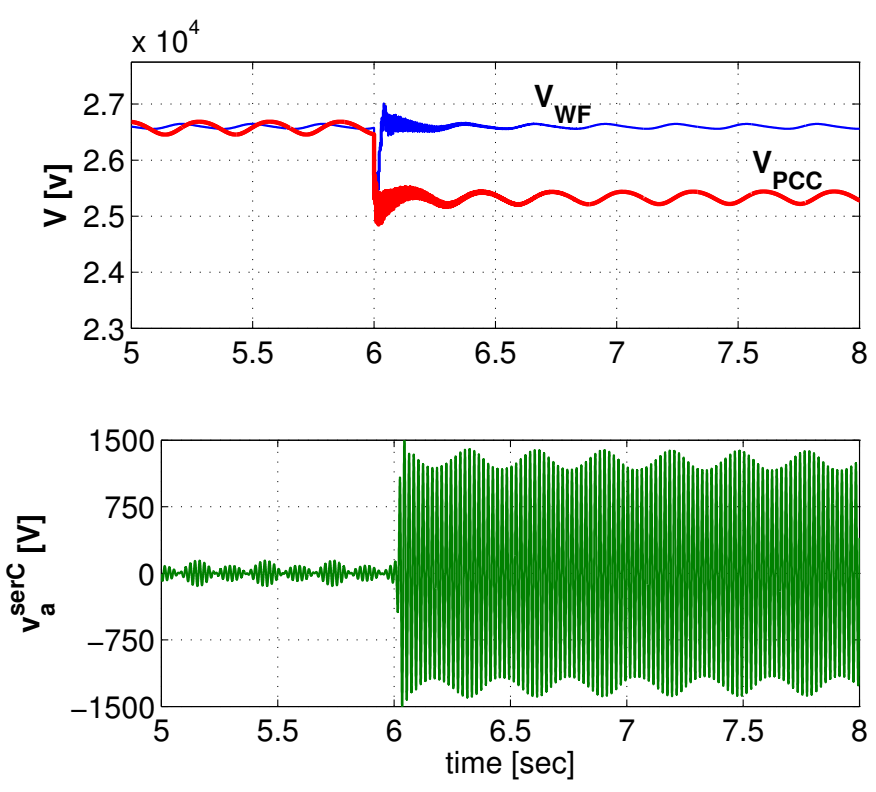

Fig. 11. Voltage at WF, at PCC, and series injected voltage at " $a$ " phase
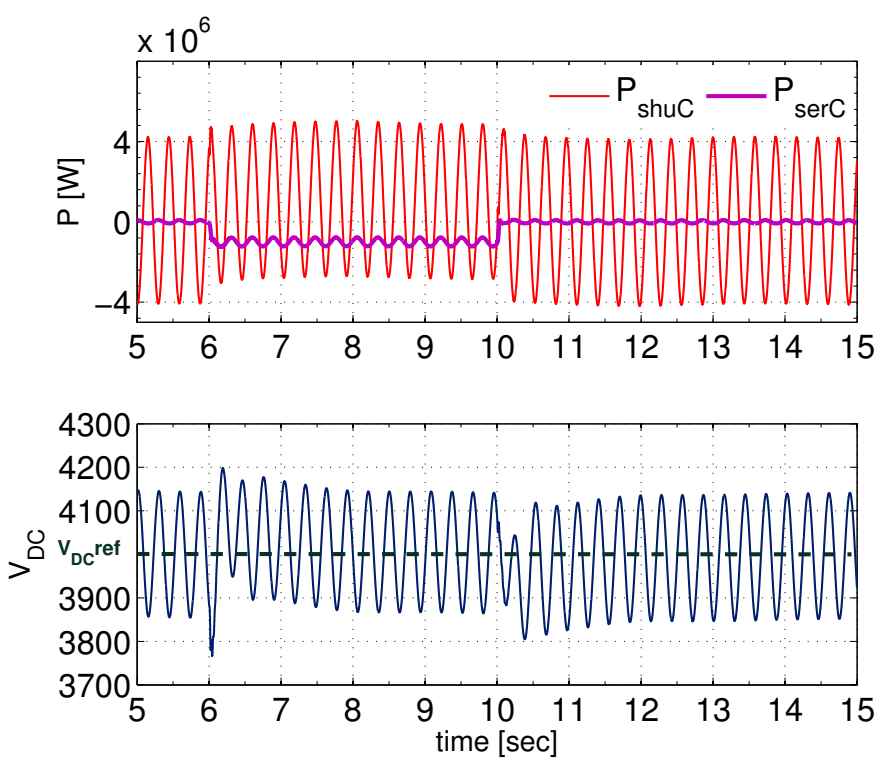

Fig. 12. Shunt and series converter active-power; and DC-bus voltage

Fig.11 shows the PCC and WF terminal voltages, and series injected voltage at "a" phase. In this figure is clearly seen a sudden change in PCC voltage, while WF terminal voltage remains almost constant due to series converter action.

In the upper curve of Fig.12 is seen shunt and series converter active-power behaviour.

The mean power injected(absorbed) by series converter is absorbed(injected) by shunt converter, because of DC voltage regulation loop action (Fig.6). So, the step in series converter active power, is the same but opposite sign, that shunt converter power. Fig. 12 also shows DC-bus voltage, and is clearly seen the VDC control action.
VDC mean value is maintained at its reference level, while ripple is not rejected.

\section{CONCLUSION}

In this paper, a new compensation strategy implemented using an UPQC type compensator was presented, to connect SCIG based wind farms to weak distribution power grid. The proposed compensation scheme enhances the system power quality, exploiting fully DC-bus energy storage and active power sharing between UPQC converters, features not present in DVR and D-Statcom compensators. The simulation results show a good performance in the rejection of power fluctuation due to "tower shadow effect" and the regulation of voltage due to a sudden load connection. So, the effectiveness of the proposed compensation approach is demonstrated in the study case. In future work, performance comparison between different compensator types will be made.

\section{ACKNOWLEDGMENTS}

The authors would like to thank to Fundación YPF, to $\mathrm{La}$ Plata National University - UNLP, to National Agency of Science and Technology Promotion ANPCyT (PICT08/11-0535), and to Comision Nacional de Investigaciones Científicas CONICET, by them financial support.

\section{REFERENCES}

[1] M.P. Pálsson, K. Uhlen, J.O.G. Tande. "Large-scale Wind Power Integration and Voltage Stability Limits in Regional Networks"; IEEE 2002. p.p. $762-769$

[2] P. Ledesma, J. Usaola, J.L. Rodriguez "Transient stability of a fixed speed wind farm" Renewable Energy 28, 2003 pp.1341-1355

[3] P. Rosas "Dynamic influences of wind power on the power system". Technical report RISØR-1408. Ørsted Institute. March 2003.

[4] R.C. Dugan, M.F. McGranahan, S. Santoso, H.W. Beaty "Electrical Power Systems Quality" 2nd Edition McGraw-Hill, 2002. ISBN 0-07138622-X

[5] P. Kundur "Power System Stability and Control" McGraw-Hill, 1994. ISBN 0-07-035958-X

[6] N. G. Hingorani y L. Gyugyi. "Understanding FACTS". IEEE Press; 2000.

[7] Z. Saad-Saoud, M.L. Lisboa, J.B. Ekanayake, N. Jenkins and G. Strbac "Application of STATCOM's to wind farms" IEE Proc. Gen. Trans. Distrib. vol. 145, No. 5; Sept. 1998

[8] T. Burton, D. Sharpe, N. Jenkins, E. Bossanyi "Wind Energy Handbook" John Wiley \& Sons, 2001. ISBN 0-471-48997-2.

[9] A. Ghosh, G. Ledwich "Power Quality Enhancement Using Custom Power Devices” Kluwer Academic Publisher, 2002. ISBN 1-4020-71809

[10] C. Schauder, H. Mehta "Vector analysis and control of advanced static VAR compensators" IEE PROCEEDINGS-C, Vol.140, No.4, July 1993.

[11] E.M. Sasso, G.G. Sotelo, A.A. Ferreira, E.H. Watanabe, M. Aredes, P.G. Barbosa, "Investigação dos Modelos de Circuitos de Sincronismo Trifásicos Baseados na Teoria das Potências Real e Imaginária Instantâneas (p-PLL e q-PLL)", In: Proc. (CDROM) of the CBA 2002 XIV Congresso Brasileiro de Automtica, pp. 480-485, Natal RN, Brasil, 1-4, Sep. 2002

[12] International Electrotechnical Commission "INTERNATIONAL STANDARD IEC 61000-4-15: Electromagnetic compatibility (EMC) Part 4: Testing and measurement techniques Section 15: Flickermeter Functional and design specifications." Edition 1.1 2003

[13] H. Akagi, E. H. Watanabe, M. Aredes "Instantaneous power theory and applications to power conditioning", John Wiley \& Sons, 2007. ISBN 978-0-470-10761-4. 